\title{
Systolic compression of left main coronary artery by left ventricular pseudoaneurysm complicated by critical stenosis of left main coronary artery
}

Kurt A. Duncan, Rishi Sukhija, Wilbert S. Aronow, Albert J. Deluca, Craig Monsen, Anthony L. Pucillo

Cardiology Division, Department of Medicine, New York Medical College, Valhalla, New York, USA

Submitted: 23 December 2010

Accepted: 22 April 2011

Arch Med Sci 2012; 8, 5: 931-933

DOI: 10.5114/aoms.2012.31624

Copyright @ 2012 Termedia \& Banach

A 69-year-old man was admitted to the hospital with complaints of exertional substernal chest pain and dyspnea for 3 weeks. His medical history consisted of dyslipidemia, type 2 diabetes mellitus, and valvular heart disease. He had a mitral commissurotomy through a left thoracotomy for mitral stenosis at age 16 years followed by mitral valve replacement with a $25 \mathrm{~mm}$ Carpentier Edwards bovine pericardial prosthesis in February, 2007. He also had a aortic valve replacement with a $19 \mathrm{~mm}$ Carpentier Edwards bovine pericardial prosthesis at that time.

On this admission, he had a maximum troponin I level of 0.12 (normal $<0.05 \mathrm{ng} / \mathrm{ml}$ ), a creatine kinase-MB fraction of 3.4 (normal $<5.0 \mathrm{ng} / \mathrm{ml}$ ), and a creatine phosphokinase of 288 (normal 35-232 U/l). Coronary angiography revealed near complete systolic obliteration of the left main coronary artery with normal caliber in diastole and discrete stenosis of the mid left anterior descending coronary artery resulting in $40 \%$ obstruction of the vessel (Figure $1 \mathrm{~A}$ ). Left ventriculography revealed systolic aneurysmal dilatation of a segment of the left ventricle (LV) compressing the left main coronary artery in systole and a LV ejection fraction of 50\% (Figure $1 \mathrm{~B}$ ).

A thoracic computed tomography (CT) scan and a transesophageal echocardiogram (TEE) were obtained to provide anatomical delineation of the LV pseudoaneurysm The thoracic CT scan revealed an abnormal $3 \mathrm{~cm} \times 2.4 \mathrm{~cm}$ contrast-filled structure to the left of the aorta, superior to the LV outflow tract, and inferior to the left main coronary artery likely representing a LV pseudoaneurysm. The TEE showed a normal LV ejection fraction, a small inferoposterior wall hypokinesis, and a LV pseudoaneurysm with a $1.3 \mathrm{~cm}$ opening originating below the mitral annulus anteriorly adjacent to the left atrial appendage extending superiorly to the left main coronary artery.

The patient subsequently had a bovine patch repair of the LV pseudoaneurysm with resection of the left atrial appendage. A coronary angiogram obtained after surgery demonstrated a discrete fixed stenosis of the mid left main coronary artery resulting in $70 \%$ obstruction of the vessel (Figure 2). Intravascular ultrasound of the left main coronary artery stenosis revealed a cross sectional area of $2.9 \mathrm{~mm}^{2}$.

The left main coronary artery was predilated with a $3.5 \mathrm{~mm} \times 9 \mathrm{~mm}$ balloon inflated to $8 \mathrm{~atm}$ for $6 \mathrm{~s}$. The stenosis was treated with a $4.0 \mathrm{~mm}$ $\times 12 \mathrm{~mm}$ everlimus drug-eluting stent that was deployed at $8 \mathrm{~atm}$ for

\author{
Corresponding author: \\ Wilbert S. Aronow MD \\ Cardiology Division \\ New York Medical College \\ Macy Pavilion, Room 138 \\ Valhalla, NY 10595, USA \\ Phone: (914) 493-5311 \\ Fax: (914)-235-6274 \\ E-mail: wsaronow@aol.com
}



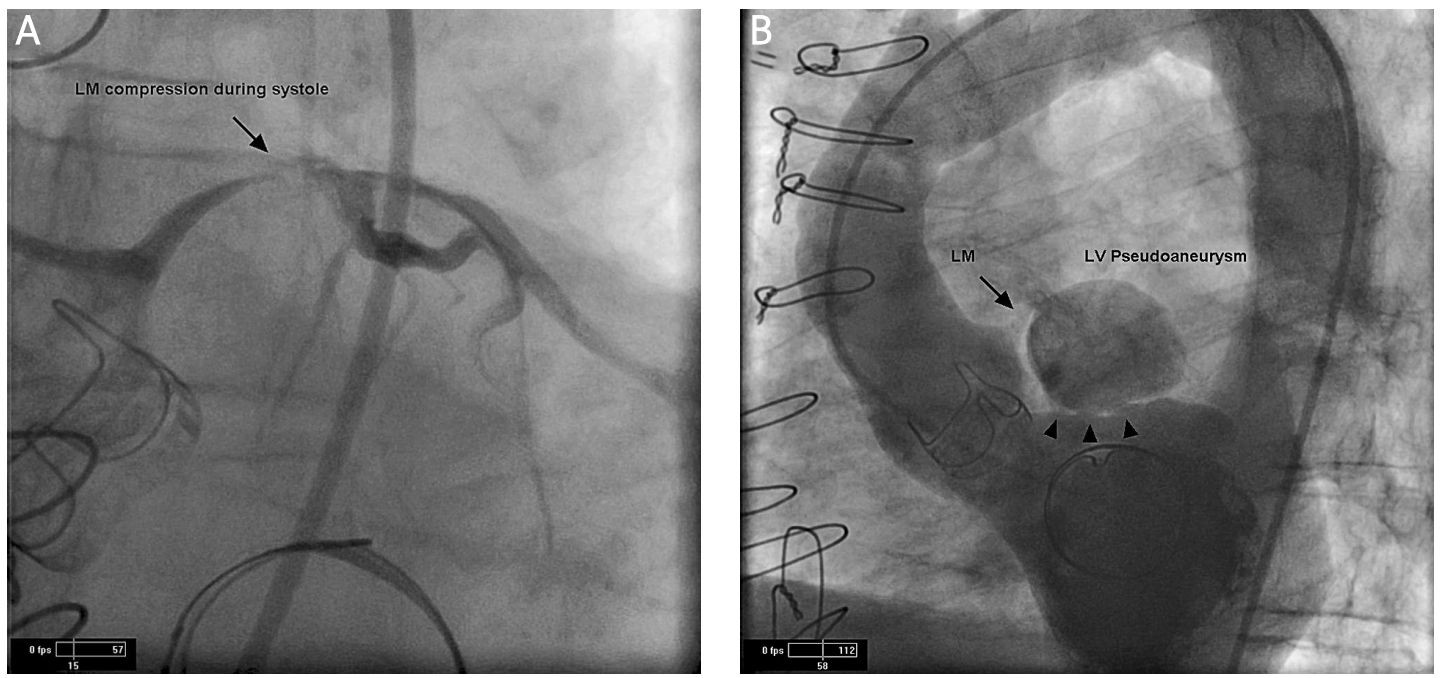

Figure 1. Findings on the initial cardiac catheterization. A - Baseline coronary angiogram in left anterior oblique caudal view demonstrating systolic compression of the left main coronary artery (LM). B - Left anterior oblique cranial view of initial left ventriculogram showing left ventricular pseudoaneurysm compressing the LM during systole. Arrowheads indicate LV pseudoaneurysm stalks

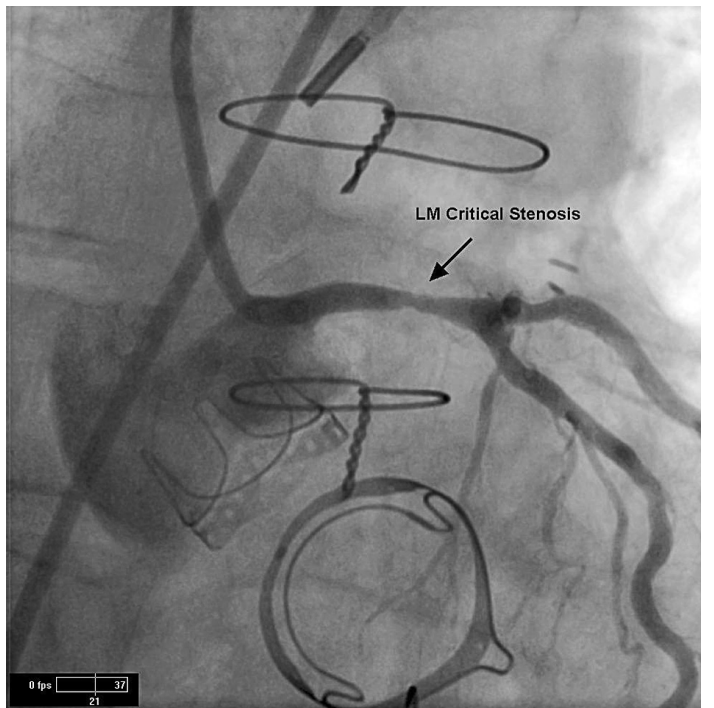

Figure 2. Coronary angiogram in right anterior oblique caudal view of LM after resection of LV pseudoaneurysm showing evidence of critical LM stenosis

$12 \mathrm{~s}$ with excellent results (Figures 3 and 4). Intravascular ultrasound imaging after percutaneous coronary intervention revealed a well apposed stent.

A LV pseudoaneurysm is an incomplete rupture of the LV myocardium that is contained by organized LV thrombus, adherent scar tissue, and portions of the epicardum and parietal pericardium. In comparison to a true LV aneurysm, the LV pseudoaneurysm has a maximal neck to internal orifice width ratio of $\leq 0.5$, a saccular or globular chamber, and a turbulent Doppler flow pattern through the neck [1]. The LV pseudoaneurysm can drain off significant portions of each LV stroke volume.

A LV pseudoaneurysm can develop due to transmural myocardial infarction, previous ventriculoto-

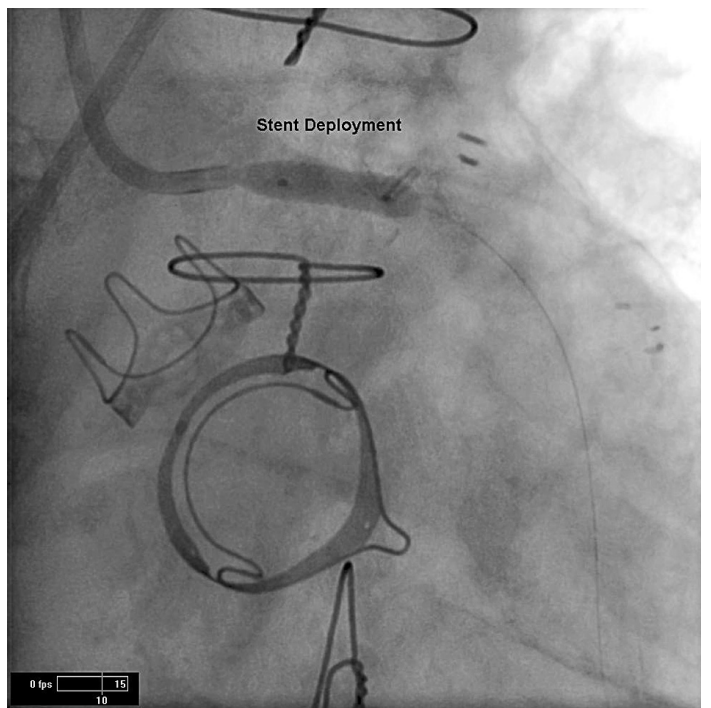

Figure 3. Coronary angiogram displaying deployment of $4.0 \mathrm{~mm} \times 12 \mathrm{~mm}$ PROMOS stent to the LM on right anterior oblique caudal view

my, replacement of the mitral valve, trauma, or infective endocarditis. It occurs in $0.02 \%$ to $2.0 \%$ of mitral valve replacement surgeries.

Factors predisposing to LV psudoaneurysm include resection of the posterior leaflet of the mitral valve, excessive decalcification of the mitral annulus, placement of an oversized mitral valve prosthesis, and reoperation for mitral valve replacement [2]. The LV pseudoaneurysm following mitral valve replacement tends to be subannular in location [3].

Congestive heart failure, chest pain, and dyspnea are the most frequently reported symptoms associated with LV pseudoaneurysm. Approximately $70 \%$ of patients have systolic heart murmurs. A pansystolic murmur due to leaking of blood 


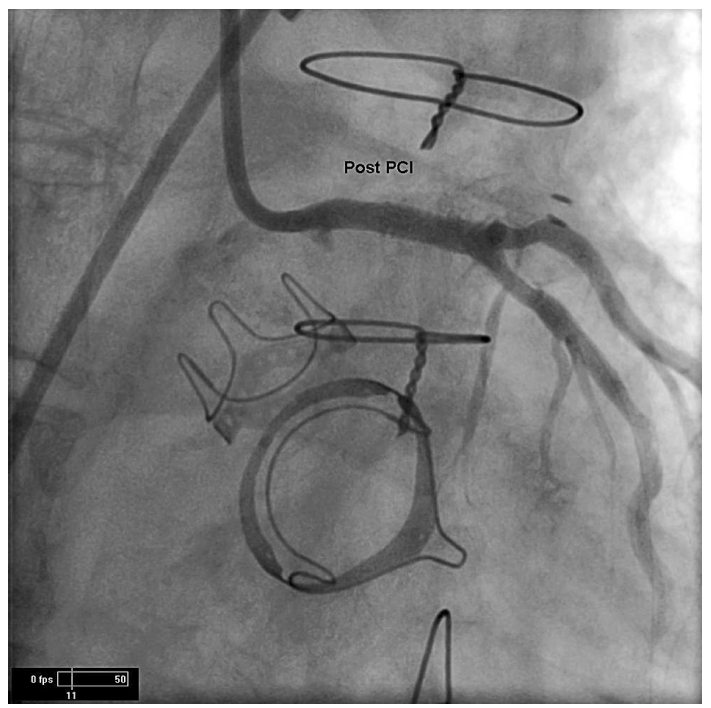

Figure 4. Right anterior oblique cranial view of LM after deployment of $4.0 \mathrm{~mm} \times 12 \mathrm{~mm}$ PROMOS stent. after percutaneous coronary intervention (post $\mathrm{PCI}$ )

into the LV pseudoaneurysm may be heard on auscultation [4]. The majority of patients have electrocardiographic abnormalities which are usually nonspecific ST-segment changes. Lethal complications of LV pseudoaneurysm are LV failure, LV thrombus formation, embolization, rupture of the aneurysm and death [5].

To the best of our knowledge, there is only one published case of a patient with a history of open mitral commissurotomy and annuloplasty, aortic valve and mitral valve replacement presenting with chest pain and dyspnea with subsequent development of a LV pseudoaneurysm causing systolic compression of the left main coronary artery [6]. Unique to our case was critical left main coronary artery stenosis seen on coronary angiography after surgery which was successfully treated with percutaneous coronary intervention.

\section{References}

1. Reeves S, May B. Contained rupture of a left ventricular pseudoaneurysm. Echo Rounds 2007; 105: 38-9.

2. Pretre R, Linka A, Jenni R, Turina M. Surgical treatment of acquired left ventricular pseudoaneurysm. Ann Thorac Surg 2000; 60: 553-7.

3. Naboodiri N, Dora S, Thomas B, Misra M. Subannular left ventricular pseudoaneurysm following mitral valve replacement. J Cardiothorac Surg 2008; 3: 28.

4. Ono M, Wolf R. Left ventricular pseudoaneurysm late after mitral valve replacement. Ann Thorac Surg 2002; 73: 1303-5.

5. Lanjewar C, Thakkar B, Kerkar P, Khandeparkar J. Submitral left ventricular pseudoaneurysm after mitral valve replacement: early diagnosis and successful repair. Interact CardioVasc Thorac Surg 2007; 6: 505-7.

6. Suda H, Ikeda K, Doi K, Shiraishi R, Furukawa K, Ito T. Successful repair of left ventricular pseudoaneurysm after mitral reoperation under hypothermic circulatory arrest. Jpn J Thorac Cardiovasc Surg 2003; 51: 18-20. 